\title{
Sikap Kerja Lebih Ergonomis Menurunkan Gaya Kompresi Tulang Belakang dan Keluhan Muskuloskeletal serta Meningkatkan Produktivitas
}

\author{
Komang Ayu Cintya Dewi ${ }^{1}$, Ketut Tirtayasa ${ }^{2}$, dan Luh Made Indah Sri Handari ${ }^{3}$ \\ ${ }^{1}$ Prodi Teknik Elektromedik, Fakultas Bisnis, Teknologi, Sosial dan Humaniora, Universitas Bali \\ Internasional \\ ${ }^{2,3}$ Program Studi Ergonomi Fisiologi Kerja, Pascasarjana Universitas Udayana \\ e-mail korespondensi: wicintya@gmail.com \\ doi:https://doi.org/10.24843/JEI.2019.v05.i02.p06
}

Article Received: 16 September 2019; Accepted: 30 Desember 2019; Published: 31 Desember 2019

\begin{abstract}
Abstrak
Peran pekerja bangunan sangat penting dalam proses membangun atau merenovasi rumah. Saat pekerja bangunan mengangkat pasir menggunakan gerobak tangan, pekerja melakukan sikap membungkuk dengan beban angkat yang cukup tinggi sehingga gaya kompresi tulang belakang mencapai $7449 \mathrm{~N}$ yang termasuk dalam kategori bahaya karena melebihi batas maksimum yang rekomendasikan NIOSH. Sikap kerja tersebut juga memicu timbulnya keluhan muskuloskeletal terutama pada bagian tulang belakang. Penelitian ini bertujuan untuk mengetahui pengaruh sikap kerja yang lebih ergonomis terhadap gaya kompresi tulang belakang, keluhan muskuloskeletal dan produktivitas kerja. Sampel yang digunakan berjumlah 8 orang dengan populasi seluruh pekerja bangunan di Denpasar. Penelitian dilakukan pada bulan April-Mei 2019 di salah satu rumah yang sedang dibangun di Kota Denpasar. Pengukuran variabel gaya kompresi menggunakan analisis biomekanika melalui hitung manual dan menggunakan software 3D SSPP serta keluhan muskuloskeletal menggunakan Nordic Body Map. Hasil penelitian diperoleh bahwa sikap kerja yang lebih ergonomis pada pekerja bangunan di Denpasar dapat menurunkan gaya kompresi L5/S1 sebesar $67,25 \%$, penurunan gaya kompresi L4/L5 sebesar 64,34\%, penurunan keluhan muskuloskeletal sebesar 4,92\% ( $<<0,05)$, dan meningkatkan produktivitas kerja sebesar 5,97\% $(\mathrm{p}<0,05)$. Disimpulkan bahwa sikap kerja yang lebih ergonomis dapat menurunkan gaya kompresi, keluhan muskuloskeletal dan meningkatkan produktivitas kerja. Disarankan kepada seluruh pekerja bangunan agar menerapkan sikap kerja yang ergonomis agar terhindar dari penyakit akibat kerja.
\end{abstract}

Kata kunci: biomekanika, gaya kompresi, keluhan muskuloskeletal, produktivitas, sikap kerja

\section{Work Posture More Ergonomically Reduce Spinal Force Compression, Musculoskeletal Complaints and Increase The Productivity}

\begin{abstract}
The role of construction workers is very important in the process of building or renovating a house. When construction workers lift sand using a hand cart, workers perform a bent stance with a lifting load that is high enough so the spinal force compression reaches $7449 \mathrm{~N}$ (L5/S1) which is included in the danger category because it exceeds the maximum premissible limit by NIOSH. The work posture also triggers musculoskeletal complaints especially in the back muscles. The purpose of this study was to find out the effect of work posture that more ergonomically on spinal force compression, musculoskeletal complaints and work productivity. The population was all construction
\end{abstract}


workers in Denpasar with a sample of 8 people. The study was conducted in April-May 2019 in one of the houses that were build in the city of Denpasar. Measurement of spinal force compression variables using biomechanical analysis through manual count and using 3D SSPP software and musculoskeletal complaints using Nordic Body Map. The results showed work posture that more ergonomically in construction workers in Denpasar could reduce respectively L5/S1 compression force $67.25 \%$, decrease in L4/L5 compression force 64.34\%, decrease in musculoskeletal complaints $4.92 \%(p<0.05)$, and increase work productivity of $5.97 \%$ ( $p<0.05)$. It was concluded were work posture that more ergonomically can reduce spinal force compression, musculoskeletal complaints and increase work productivity. Recommended for all construction workers to apply ergonomically work posture to avoid work-related illnesses.

Keywords: biomechanics, musculoskeletal complaints, productivity, spinal force compression, work posture.

\section{PENDAHULUAN}

Industri properti yang meningkat diikuti oleh bertambahnya kebutuhan jumlah pekerja bangunan. Peran pekerja bangunan sangat penting dalam proses membangun atau merenovasi rumah. Namun sering kali para pekerja bangunan mengabaikan aspek kesehatan dan keselamatan kerja. Berdasarkan studi pendahuluan pada pekerja bangunan di daerah Denpasar, ditemukan sikap pekerja yang membungkuk saat mulai mengangkat gerobak tangan dengan beban angkat yang cukup tinggi dan pekerjaan tersebut dilakukan secara berulang. Berdasarkan analisis REBA, diperoleh skor sebesar 8 yang artinya pekerja memiliki risiko yang tinggi dan harus segera diberi intervensi.

Melalui analisis biomekanika ditemukan pula bahwa gaya kompresi yang dialami oleh pekerja pada L5/S1 sebesar $7449 \mathrm{~N}$ dan pada L4/L5 sebesar $7348 \mathrm{~N}$. Menurut NIOSH, batasan gaya angkat normal (AL) sebesar $3400 \mathrm{~N}$ dan gaya tekan maksimum (MPL) sebesar $6400 \mathrm{~N}$. Berdasarkan hal tersebut, nilai rerata gaya kompresi L5/S1 dan L4/15 melebihi nilai maximum pressure load (MPL). Hal tersebut sangat membahayakan kesehatan para pekerja, karena jika tulang belakang terus menerus diberi tekanan yang tinggi maka dampak jangka panjangnya dapat mengakibatkan pecahnya disk pada tulang belakang yang berujung pada kelumpuhan. Besarnya gaya kompresi tersebut mengakibatkan otot yang menyangga tulang belakang harus berkontraksi dengan kuat yang menyebabkan terjadinya keluhan muskuloskeletal pada pekerja dibagian punggung (43\%), pinggang (53\%) dan bokong (60\%).

Berdasarkan penelitian terdahulu, perbaikan cara angkat-angkut bahan bangunan menurunkan aktivitas otot erector spinae dan keluhan muskuloskeletal (Muliarta, 2015). Penelitian yang sama dilakukan oleh Suarbawa (2017) yang menyimpulkan bahwa perbaikan sikap kerja menurunkan beban kerja, keluhan muskuloskeletal, kelelahan, dan peningkatan produktivitas kerja pada proses pembersihan garam. Kurangnya pengetahuan pekerja tentang bagaimana bekerja dengan sikap kerja yang ergonomis menjadi salah satu faktor penyebab masalah tersebut.

Sikap kerja yang ergonomis bagi pekerja bangunan saat mengangkat gerobak tangan yaitu dengan cara menekukkan lutut dan sedikit berjongkok dengan tetap menjaga punggung dan kepala agar tetap lurus selama mengangkat. Sikap kerja yang lebih ergonomis tersebut sangat disarankan karena setelah dianalisis secara biomekanika diperoleh nilai gaya kompresi L5/S1 sebesar $3606 \mathrm{~N}$ dan gaya kompresi L4/L5 sebesar $4408 \mathrm{~N}$ yang mendekati kategori aman. Mengacu pada hal tersebut, alternatif pemecahan masalah yang dapat dilakukan yaitu dengan cara memberikan edukasi dan mengajak pekerja untuk memperbaiki sikap kerjanya menjadi lebih ergonomis. Dengan menerapkan sikap kerja yang lebih ergonomis diharapkan 
mampu menurunkan gaya kompresi tulang belakang dan keluhan muskuloskeletal, serta meningkatkan produktivitas pekerja bangunan di Denpasar, Bali.

\section{METODE}

Penelitian ini menggunakan treatment by subject design yang meliputi Periode 1 (tanpa intervensi) dan Periode 2 (dengan intervensi) diselingi dengan washing out period selama sehari pada hari Minggu untuk menghilangkan efek sisa dari Periode 1. Selanjutnya subjek diberi kesempatan untuk melakukan adaptasi selama sehari dengan sikap kerja yang lebih ergonomis. Edukasi mengenai sikap kerja yang ergonomis dilakukan saat proses adaptasi. Penelitian dilakukan pada salah satu rumah warga di daerah Denpasar, Bali yang sedang melakukan pembangunan. Penelitian dilakukan selama bulan April-Mei 2018 dengan populasi seluruh pekerja bangunan di daerah Denpasar, Bali dan jumlah sampel untuk penelitian ini sebanyak 8 pekerja yang dipilih menggunakan teknik consecutive sampling. Gaya kompresi tulang belakang diperoleh berdasarkan analisis biomekanika melalui perhitungan manual dan menggunakan aplikasi simulasi 3D SSPP. Keluhan muskuloskeletal diukur dengan kuesioner Nordic Body Map. Produktivitas kerja didapatkan melalui perbandingan antara beban yang diangkut dengan skor keluhan muskuloskeletal yang dialami pekerja. Data yang telah diperoleh selanjutnya dianalisis secara statistik.

\section{HASIL DAN PEMBAHASAN}

Semua subjek hadir selama penelitian dan dapat mengikuti kegiatan penelitian dengan baik. Data karakteristik subjek penelitian pada 8 pekerja disajikan pada Tabel 1 .

Tabel 1

Karakteristik Subjek Penelitian

\begin{tabular}{lcrc}
\hline Variabel & $\mathrm{N}$ & Rerata $+\mathrm{SB}$ & Rentangan \\
\hline Umur (th) & 8 & $31,88 \pm 5,27$ & $25-39$ \\
Berat badan $(\mathrm{kg})$ & 8 & $60,48 \pm 3,64$ & $55,2-64,7$ \\
Tinggi badan $(\mathrm{cm})$ & 8 & $167,50 \pm 0,05$ & $160-175$ \\
Indeks massa tubuh $\left(\mathrm{kg} / \mathrm{m}^{2}\right)$ & 8 & $21,56 \pm 0,47$ & $20,62-22,00$ \\
Pengalaman kerja $(\mathrm{bln})$ & 8 & $43,75 \pm 20,69$ & $15-72$ \\
\hline
\end{tabular}

Pada penelitian ini Indeks Massa Tubuh (IMT) subjek dikontrol dalam batas normal, sehingga mempunyai status gizi yang sama dan tidak berpengaruh pada hasil penelitian. Tinggi badan, berat badan dan indeks massa tubuh mempunyai hubungan yang kuat terhadap risiko terjadinya gangguan muskuloskeletal. Pekerja yang memiliki IMT yang tinggi memiliki risiko terkena gangguan muskuloskeletal yang lebih tinggi (Suputra, 2003). Pekerja memiliki umur dengan rentang 25-39 tahun yang merupakan umur yang produktif untuk bekerja. Kekuatan fisik pada rentangan umur 50-60 tahun hanya mencapai 75-85\% dibandingkan dengan orang yang berumur 25-45 tahun (Pheasant, 1991).

Subjek penelitian memiliki pengalaman kerja yang dirasa cukup dengan rerata pengalaman kerja 15-72 bulan sehingga dapat dikatakan bahwa subjek penelitian dalam kondisi sehat dan memiliki kemampuan atau keahlian kerja yang relatif sama. Hasil penelitian karakteristik subjek menunjukkan subjek pekerja bangunan di Denpasar masih memiliki kemampuan kerja optimal sehingga memungkinkan untuk melakukan aktivitas secara normal dan sesuai dengan kriteria sampel.

Kondisi lingkungan kerja dapat berpengaruh terhadap kenyamanan dan kesehatan pekerja bangunan di Denpasar. Lingkungan kerja yang kurang baik dapat menyebabkan 
ketidaknyamanan dan gangguan kesehatan bagi para pekerja. Sumber pencahayaan di lingkungan kerja pekerja bangunan berasal dari cahaya matahari dengan rerata intensitas cahaya sebesar 298,36 lux. Intensitas cahaya tersebut telah sesuai dengan nilai yang direkomendasikan untuk pekerja industri yaitu 200-300 lux (Kroemer dan Grandjean, 2010). Kebisingan adalah suara yang tidak dikehendaki sehingga menimbulkan gangguan pendengaran dengan nilai ambang kebisingan yaitu 85 dB (Manuaba, 2000). Rerata kebisingan yang terjadi di tempat penelitian sebesar 69,6 dB yang tidak melebihi ambang batas yang direkomendasikan.

Tabel 2

Analisis Kondisi Lingkungan

\begin{tabular}{|c|c|c|c|c|c|}
\hline \multirow{2}{*}{ Variabel } & \multicolumn{2}{|c|}{ Periode 1} & \multicolumn{2}{|c|}{ Periode 2} & \multirow[b]{2}{*}{$\mathrm{p}$} \\
\hline & Rerata & SB & Rerata & SB & \\
\hline Suhu $\left({ }^{0} \mathrm{C}\right)$ & 29,70 & 0,41 & 29,53 & 0,45 & 0,26 \\
\hline Kelembaban Relatif (\%) & 79,70 & 0,95 & 79,20 & 1,03 & 0,09 \\
\hline Intensitas Cahaya (Lux) & 298,44 & 8,42 & 298,28 & 7,66 & 0,96 \\
\hline Kebisingan $(\mathrm{dB})$ & 69,60 & 0,58 & 69,54 & 0,62 & 0,83 \\
\hline
\end{tabular}

Berdasarkan Tabel 2, seluruh variabel kondisi lingkungan memiliki nilai $\mathrm{p}>0,05$ yang artinya suhu, kelembaban, intensitas cahaya, dan kebisingan tidak ada perbedaan yang bermakna pada Periode 1 dan Periode 2 . Hal tersebut menunjukkan bahwa kondsi lingkungan dalam keadaan yang sama pada Periode 1 dan 2 sehingga tidak memberi pengaruh terhadap interverensi yang diberikan.

Gaya kompresi tulang belakang adalah gaya tekan pada intervertebral disk yang biasa terjadi antara lumbar kelima dengan sacrum pertama (L5/S1) dan lumbar keempat dengan lumbar kelima (L4/L5). Gaya kompresi pada L5/S1 diperoleh menggunakan perhitungan biomekanika dengan menganalisis sudut pada setiap segmen (Gambar 1) dan menghitung gaya kompresi dengan menganalisis momen gaya pada setiap segmen.

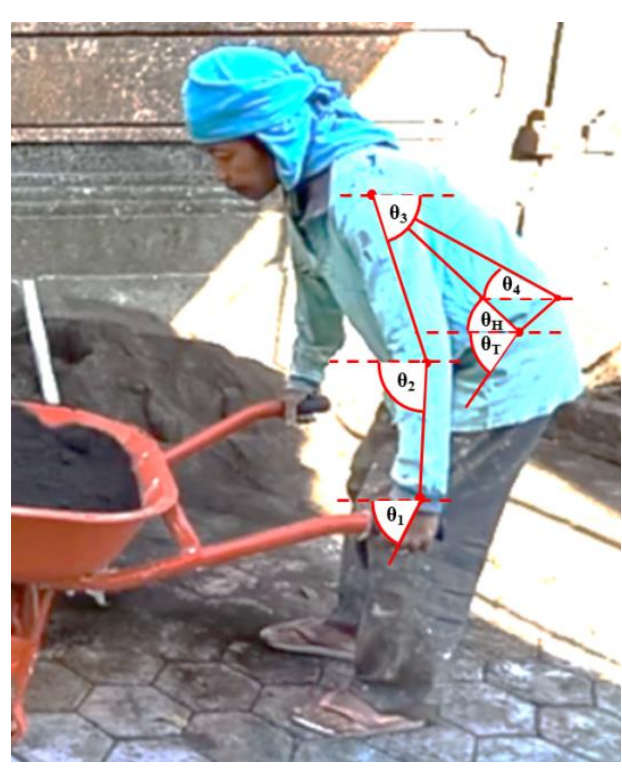

(a)

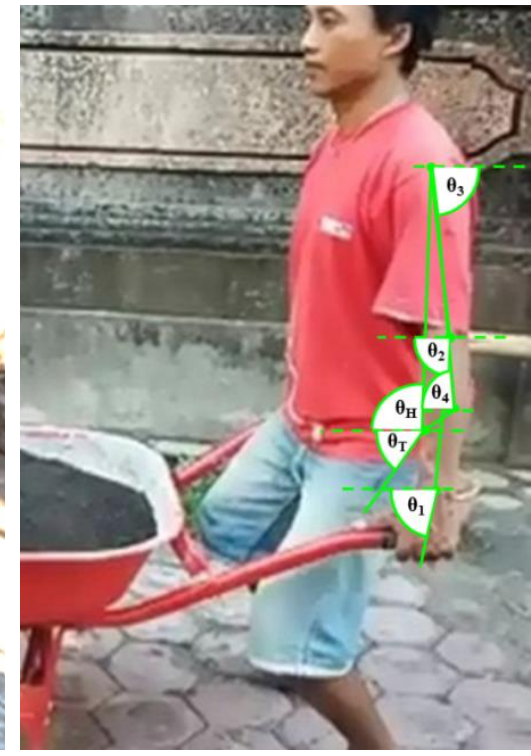

(b)

Gambar 1. Analisis Sudut Salah Satu Sampel. (a) Periode 1 (b) Periode 2 
Setiap sampel dilakukan pengukuran sudut seperti pada Gambar 1 dengan nilai yang dinyatakan pada Tabel 3. Data antropometeri segmen tubuh pada pekerja tersebut, yaitu panjang telapak tangan $\left(\mathrm{SL}_{1}\right)$ 0,11 m; panjang lengan bawah $\left(\mathrm{SL}_{2}\right)$ 0,26 m; panjang lengan atas $\left(\mathrm{SL}_{3}\right)$ 0,28 m; panjang punggung $\left(\mathrm{SL}_{4}\right) 0,52 \mathrm{~m}$. Pekerja tersebut memiliki berat badan $642 \mathrm{~N}$ dengan berat beban pada tangan sebesar $392 \mathrm{~N}$ yang dihitung berdasarkan momen gaya.

Tabel 3

Data Sudut pada Setiap Segmen Salah Satu Pekerja

\begin{tabular}{ccccccc}
\hline Sudut & $\theta_{1}$ & $\theta_{2}$ & $\theta_{3}$ & $\theta_{4}$ & $\theta_{\mathrm{H}}$ & $\theta_{\mathrm{T}}$ \\
\hline Periode 1 & $65^{\mathrm{o}}$ & $85^{\mathrm{o}}$ & $72^{\circ}$ & $29^{\mathrm{o}}$ & $42^{\mathrm{o}}$ & $55^{\mathrm{o}}$ \\
Periode 2 & $80^{\mathrm{o}}$ & $85^{\mathrm{o}}$ & $85^{\mathrm{o}}$ & $80^{\mathrm{o}}$ & $90^{\mathrm{o}}$ & $55^{\mathrm{o}}$ \\
\hline
\end{tabular}

Perhitungan manual gaya kompresi L5/S1 menggunakan analisis biomekanika pada salah satu sampel dengan sikap kerja semula (Periode 1) dan sikap kerja ergonomis (Periode 2) disajikan pada Tabel 4.

Tabel 4

Analisis Biomekanika pada Salah Satu Sampel

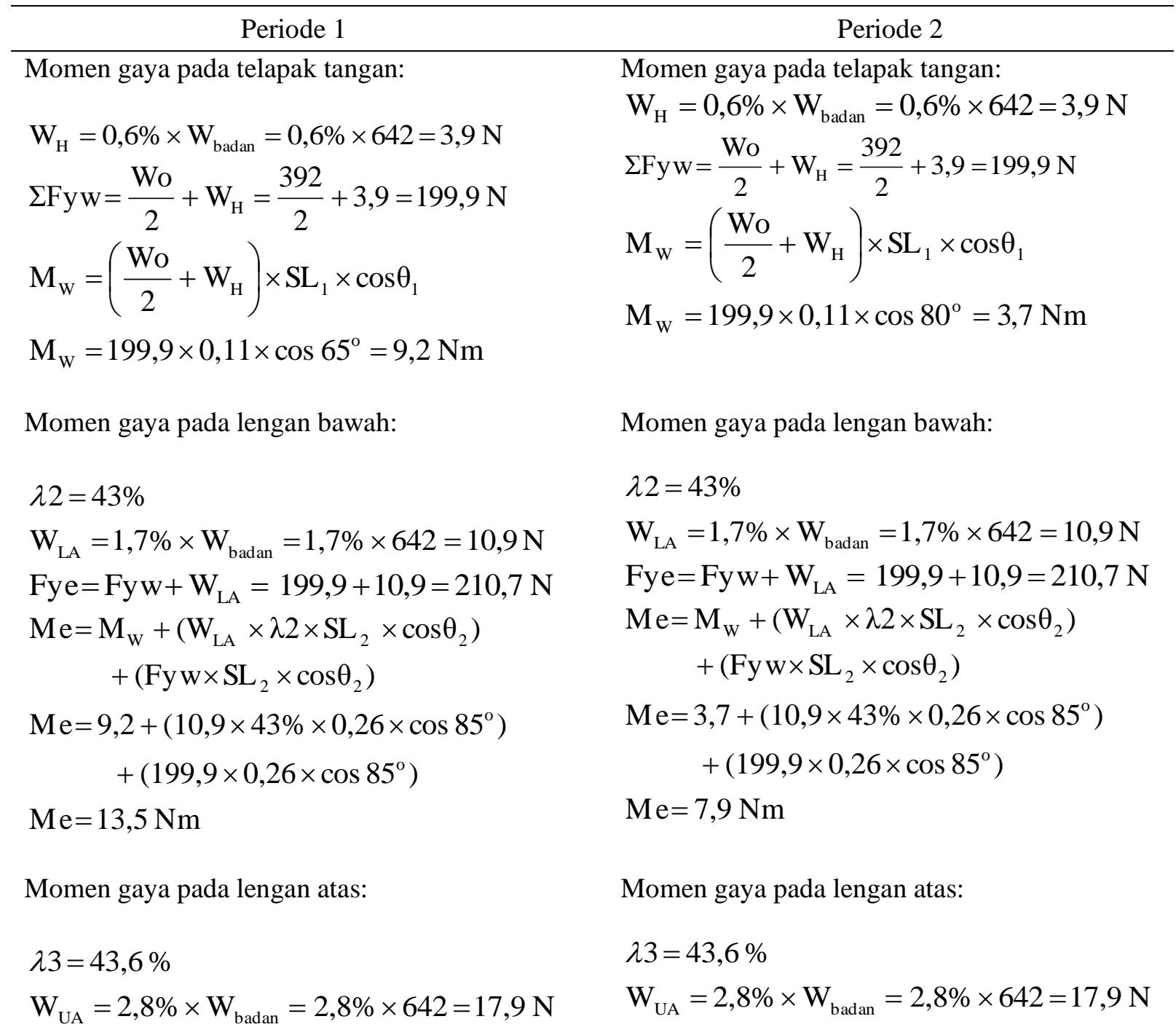




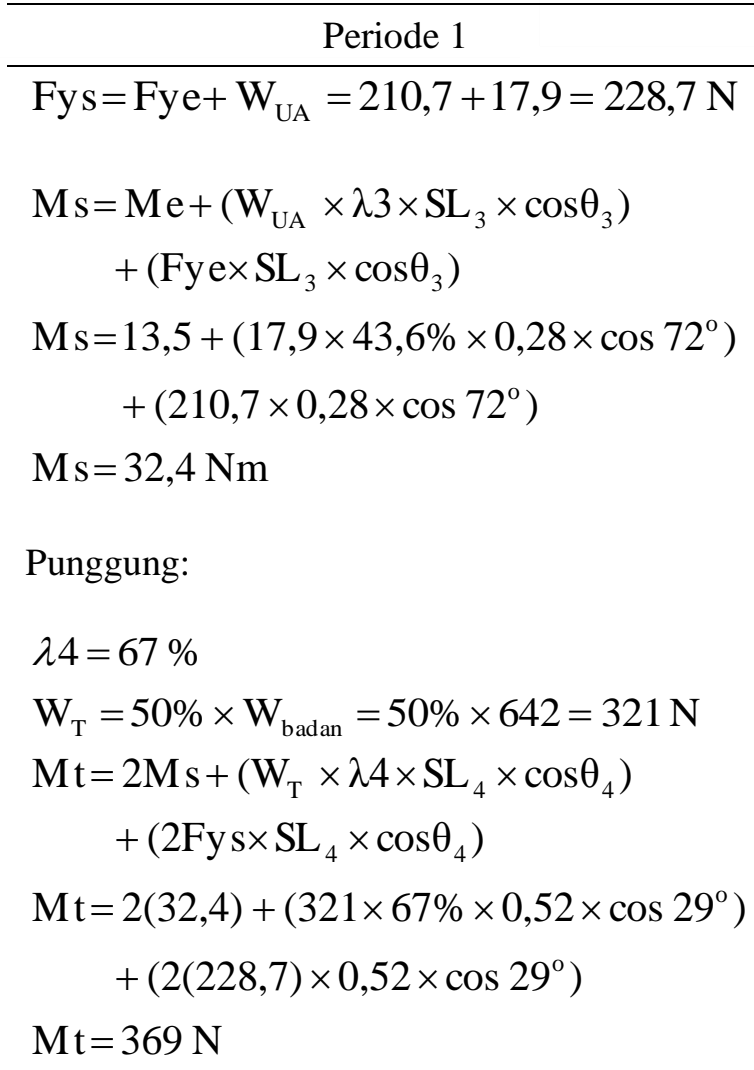

Gaya perut $\left(\mathrm{F}_{\mathrm{A}}\right)$ dan tekanan perut $\left(\mathrm{P}_{\mathrm{A}}\right)$ :

$$
\begin{aligned}
& P_{A}=\frac{10^{-4}\left[43-0,36\left(\theta_{\mathrm{H}}+\theta_{\mathrm{T}}\right)\right][\mathrm{Mt}]^{1,8}}{75} \\
& \mathrm{P}_{\mathrm{A}}=\frac{10^{-4}[43-0,36(42+55)][369]^{1,8}}{75} \\
& \mathrm{P}_{\mathrm{A}}=0,45 \mathrm{~N} / \mathrm{m}^{2} \\
& \mathrm{~F}_{\mathrm{A}}=\mathrm{P}_{\mathrm{A}} \times \mathrm{A}=0,45 \times 0,0465=0,01 \mathrm{~N}
\end{aligned}
$$

Gaya otot pada spinal erector $\left(\mathrm{F}_{\mathrm{M}}\right)$ :

$$
\begin{aligned}
& F_{M} \cdot E=M_{t}-F_{A} \cdot D \\
& F_{M} \cdot 0,05=369-0,01 \cdot 0,11 \\
& F_{M}=7381,27 N
\end{aligned}
$$

Berat yang terjadi pada gaya kompresi:

$$
\begin{aligned}
\mathrm{W}_{\text {tot }}= & \mathrm{Wo}_{\mathrm{o}}+2 \mathrm{~W}_{\mathrm{H}}+2 \mathrm{~W}_{\mathrm{LA}}+2 \mathrm{~W}_{\mathrm{UA}}+\mathrm{W}_{\mathrm{T}} \\
\mathrm{W}_{\text {tot }}= & 392+2(3,9)+2(10,9)+2(19,7) \\
& +321=778,5 \mathrm{~N}
\end{aligned}
$$

Gaya kompresi pada L5/S1:

$$
\begin{aligned}
& \mathrm{Fc}=\mathrm{W}_{\text {tot }} \cdot \cos \theta_{4}-\mathrm{F}_{\mathrm{A}}+\mathrm{F}_{\mathrm{M}} \\
& \mathrm{Fc}=778,5 \cdot \cos 29^{\circ}-0,01+7381,27 \\
& \mathrm{Fc}=8059 \mathrm{~N}
\end{aligned}
$$

\section{Periode 2}

$$
\begin{aligned}
\text { Fys }= & \text { Fye }+\mathrm{W}_{\mathrm{UA}}=210,7+17,9=228,7 \mathrm{~N} \\
\mathrm{Ms}= & \mathrm{Me}+\left(\mathrm{W}_{\mathrm{UA}} \times \lambda 3 \times \mathrm{SL}_{3} \times \cos \theta_{3}\right) \\
& +\left(\mathrm{Fye} \times \mathrm{SL}_{3} \times \cos \theta_{3}\right) \\
\mathrm{Ms}= & 7,9+\left(17,9 \times 43,6 \% \times 0,28 \times \cos 85^{\circ}\right) \\
& +\left(210,7 \times 0,28 \times \cos 85^{\circ}\right) \\
\mathrm{Ms}= & 12,8 \mathrm{Nm}
\end{aligned}
$$

Punggung:

$$
\begin{aligned}
\lambda 4= & 67 \% \\
\mathrm{~W}_{\mathrm{T}} & =50 \% \times \mathrm{W}_{\text {badan }}=50 \% \times 642=321 \mathrm{~N} \\
\mathrm{Mt}= & 2 \mathrm{Ms}+\left(\mathrm{W}_{\mathrm{T}} \times \lambda 4 \times \mathrm{SL}_{4} \times \cos \theta_{4}\right) \\
& +\left(2 \mathrm{Fy} \mathrm{s} \times \mathrm{SL}_{4} \times \cos \theta_{4}\right) \\
\mathrm{Mt}= & 2(12,8)+\left(321 \times 67 \% \times 0,52 \times \cos 80^{\circ}\right) \\
& +\left(2(228,7) \times 0,52 \times \cos 80^{\circ}\right) \\
\mathrm{Mt} & =85,2 \mathrm{~N}
\end{aligned}
$$

Gaya perut $\left(\mathrm{F}_{\mathrm{A}}\right)$ dan tekanan perut $\left(\mathrm{P}_{\mathrm{A}}\right)$ :

$$
\begin{aligned}
& P_{A}=\frac{10^{-4}\left[43-0,36\left(\theta_{\mathrm{H}}+\theta_{\mathrm{T}}\right)\right][\mathrm{Mt}]^{1,8}}{75} \\
& \mathrm{P}_{\mathrm{A}}=\frac{10^{-4}[43-0,36(90+55)][85,2]^{1,8}}{75} \\
& \mathrm{P}_{\mathrm{A}}=-0,03 \mathrm{~N} / \mathrm{m}^{2} \\
& \mathrm{~F}_{\mathrm{A}}=\mathrm{P}_{\mathrm{A}} \times \mathrm{A}=(-0,03) \times 0,0465=-0,0017 \mathrm{~N}
\end{aligned}
$$

Gaya otot pada spinal erector $\left(\mathrm{F}_{\mathrm{M}}\right)$ :

$$
\begin{aligned}
& F_{M} \cdot E=M_{t}-F_{A} \cdot D \\
& F_{M} \cdot 0,05=85,2-(-0,0017) \cdot 0,11 \\
& F_{M}=1704 N
\end{aligned}
$$

Berat yang terjadi pada gaya kompresi:

$$
\begin{aligned}
\mathrm{W}_{\text {tot }}= & \mathrm{Wo}_{\mathrm{o}}+2 \mathrm{~W}_{\mathrm{H}}+2 \mathrm{~W}_{\mathrm{LA}}+2 \mathrm{~W}_{\mathrm{UA}}+\mathrm{W}_{\mathrm{T}} \\
\mathrm{W}_{\text {tot }}= & 392+2(3,9)+2(10,9)+2(19,7) \\
& +321=778,5 \mathrm{~N}
\end{aligned}
$$

Gaya kompresi pada L5/S1:

$\mathrm{Fc}=\mathrm{W}_{\text {tot }} \cdot \cos \theta_{4}-\mathrm{F}_{\mathrm{A}}+\mathrm{F}_{\mathrm{M}}$

$F \mathrm{c}=778,5 \cdot \cos 80^{\circ}-(-0,0017)+1704$ $\mathrm{Fc}=1837 \mathrm{~N}$ 
Berdasarkan perhitungan pada Tabel 4, besar gaya kompresi L5/S1 pada salah satu sampel saat Periode 1 sebesar 8059 N, sedangkan saat Periode 2 sebesar 1837 N. Nilai gaya kompresi pada Periode 1 melebihi batas maksimum yang ditetapkan oleh NIOSH dan termasuk dalam kategori berbahaya, sedangkan pada Periode 2 termasuk dalam kategori aman. Tingginya nilai gaya kompresi pada Periode 1 disebabkan karena kecilnya sudut yang terbentuk antara tubuh terhadap garis horisontal $\left(\theta_{4}\right)$ sehingga membuat tingginya nilai $\cos \theta_{4}$ yang berpengaruh terhadap besarnya nilai momen gaya pada tulang belakang (Mt) dan gaya kompresi pada L5/S1. Nilai gaya kompresi tersebut memberi kontribusi terhadap besarnya gaya otot pada spinal erector $\left(\mathrm{F}_{\mathrm{M}}\right)$, karena besarnya gaya kompresi membuat gaya otot semakin berkontraksi untuk menahan struktur tulang belakang. Otot yang berkontraksi dengan tinggi tersebut dapat menyebabkan timbulnya keluhan muskuloskeletal. Selain itu, dalam jangka panjang dampak dari tingginya gaya kompresi tulang belakang yaitu cedera pada disk yang dapat berujung pada kelumpuhan.

Tabel 5

Analisis Efek Perlakuan Gaya Kompresi Tulang Belakang

\begin{tabular}{llllll}
\hline \multirow{2}{*}{ Variabel } & \multicolumn{2}{c}{ Periode 1 } & \multicolumn{2}{c}{ Periode 2 } & \multirow{2}{*}{ p } \\
\cline { 2 - 5 } & Rerata & SB & Rerata & SB & \\
\hline Gaya kompresi L5/S1 (N) & 7839,25 & 974,39 & 2054,37 & 409,22 & 0,001 \\
Gaya kompresi L4/L5 (N) & 6731,12 & 184,45 & 2400,25 & 291,44 & 0,012 \\
\hline
\end{tabular}

Hasil pada Tabel 5 menunjukkan bahwa terjadi penurunan gaya kompresi L5/S1 dan L4/L5 secara signifikan sebesar 73,79\% (L5/S1) dan 64,34\% (L4/L5) setelah mengaplikasikan sikap kerja yang ergonomis $(\mathrm{p}<0,05)$. Senada dengan penelitian yang dilakukan oleh Rochman (2105), bahwa perbaikan sikap kerja ketika melakukan aktivitas manual material handling dapat menurunkan risiko cidera tulang belakang (L5/S1). Sitanggang (2009) juga menjelaskan dalam penelitiannya bahwa perbaikan postur tubuh pada saat menggendong anak dapat mengurangi risiko cidera punggung dengan merekomendasikan beberapa model berdasarkan nilai gaya kompresi L5/S1 yang tidak melebihi batas MPL yang direkomendasikan NIOSH.

Melalui perhitungan biomekanika ditemukan bahwa semakin kecil sudut yang terbentuk antara tubuh terhadap garis horizontal maka semakin besar torsi atau momen gaya yang bekerja pada segmen punggung yang mengakibatkan besarnya gaya kompresi tulang belakang (Gambar 1). Hal tersebut menunjukkan bahwa sikap kerja yang semakin membungkuk akan menghasilkan momen gaya yang lebih besar sehingga menyebabkan gaya kompresi tulang belakang L5/S1 dan L4/L5 semakin tinggi. Selain sudut, jarak beban terhadap tumpuan tulang belakang juga mempengaruhi besarnya gaya kompresi. Semakin jauh jarak beban terhadap titik tumpu tulang belakang (Periode 1) membuat gaya kompresi lebih besar dibandingkan posisi saat beban yang diangkat mendekati titik tumpu (L5/S1 dan L4/L5) pada Periode 2 yang meminimalisir besarnya gaya tekanan terhadap titik tumpu. Senada dengan penelitian lain yang menyebutkan bahwa diperoleh rerata selisih gaya otot 150,20 N (Periode 1) dan 29,11 N (Periode 2) yang terjadi karena sikap kerja menuang adonan pada Perlakuan 1 lebih banyak menjauhi bidang median dibanding pada Periode 2 (Dinata, 2018).

Perubahan sikap kerja juga membuat turunnya skor REBA dari 8 (Periode 1) yang memiliki risiko tinggi menjadi 5 (Periode 2) yang memiliki risiko sedang. Hal tersebut menunjukkan bahwa perbaikan sikap kerja yang ergonomis dapat menurunkan risiko pada pekerja bangunan. 
Tabel 6 menunjukkan bahwa adanya penurunan keluhan muskuloskeletal secara signifikan sebesar 4,92\% setelah mengaplikasikan sikap kerja yang ergonomis. Walaupun penurunan keluhan muskuloskeletal tergolong rendah namun secara statistik menunjukkan bahwa terjadi penurunan yang signifikan antara Periode 1 dan Periode 2. Dengan demikian perbaikan sikap kerja yang ergonomis dapat menurunkan keluhan muskuloskeletal dibandingkan dengan sikap kerja semula yang tidak fisiologis. Keluhan muskuloskeletal pada tulang belakang sangat berpengaruh terhadap nilai gaya otot pada tulang belakang. Berdasarkan analisis biomekanika pada gaya kompresi, diperoleh pula nilai gaya otot pada spinal erector pada Periode 1 dan Peridode 2. Rerata gaya otot sikap kerja pada Periode 1 sebesar $7185 \mathrm{~N}$ dan pada Periode 2 gaya otot menurun sebesar $1957 \mathrm{~N}$. Hal tersebut sesuai dengan penurunan skor keluhan muskulosketetal setelah melakukan sikap yang ergonomis.

Tabel 6

Analisis Efek Perlakuan terhadap Keluhan Muskuloskeletal

\begin{tabular}{lrrrrr}
\hline \multirow{2}{*}{ Keluhan Muskuloskeletal } & \multicolumn{2}{c}{ Periode 1 } & \multicolumn{3}{c}{ Periode 2 } \\
\cline { 2 - 5 } & Rerata & SB & Rerata & SB & \\
\hline Sebelum bekerja (pre) & 28,75 & 0,70 & 28,88 & 0,64 & 0,317 \\
Setelah bekerja (post) & 35,50 & 1,07 & 33,75 & 0,70 & 0,001 \\
Selisih (pre-post) & 6,75 & 0,88 & 4,88 & 0,64 & 0,010 \\
\hline
\end{tabular}

Sesuai dengan pendapat Andreani (2013), memperbaiki sikap kerja dengan tidak melakukan posisi membungkuk dalam waktu yang cukup lama agar tidak meningkatkan keluhan subjektif. Penelitian yang dilakukan oleh Suarbawa (2017) juga menyatakan bahwa bahwa perbaikan sikap kerja pada proses pembersihan garam menyebabkan terjadi penurunan keluhan muskuloskeletal. Hasil tersebut senada dengan penelitian Muliarta (2015) yang menyatakan penerapan sikap kerja yang ergonomis mampu menurunkan keluhan muskuloskeletal seiring dengan berkurangnya ketegangan otot. Diantara semua segmen tubuh, segmen yang mengalami keluhan muskuloskeletal terbanyak adalah segmen punggung, pinggang dan bokong. Skor keluhan muskuloskeletal pada segemen terbanyak di Periode 1 dan 2 disajikan pada Gambar 2.

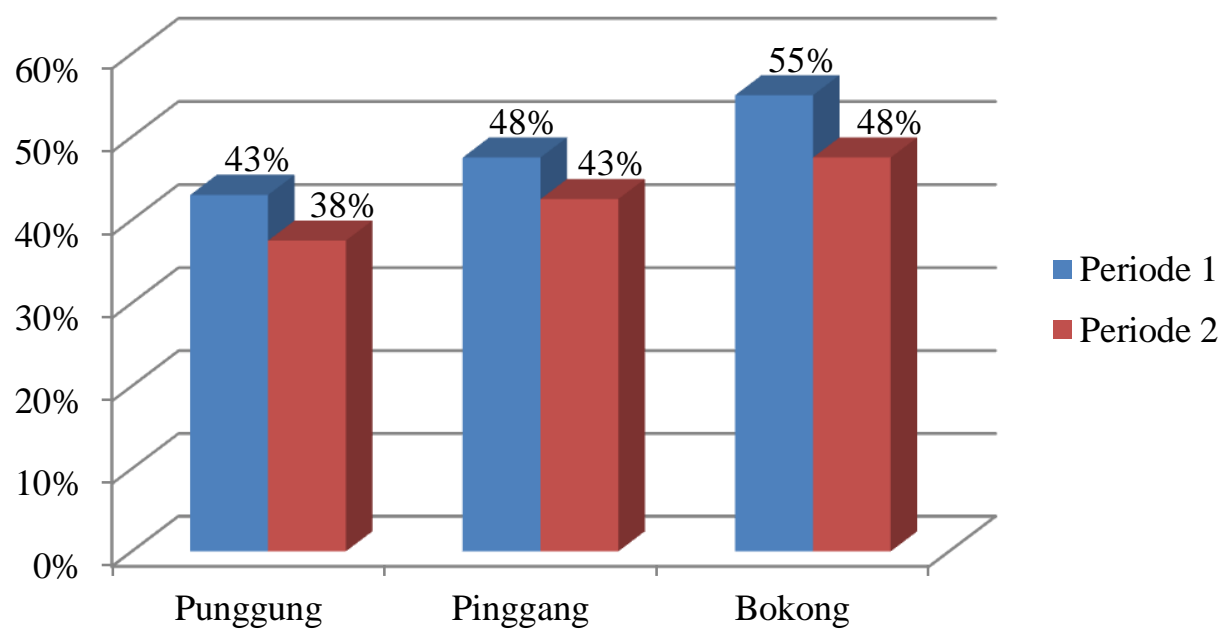

Gambar 2. Grafik Skor Keluhan Muskuloskeletal per Segmen Terbanyak 
Tingginya tingkat keluhan muskuloskeletal pada bagian tulang belakang sebanding dengan tingginya nilai gaya otot yang dialami pada tulang belakang. Keluhan muskuloskeletal pekerja bangunan disebabkan oleh tingginya gaya otot pada tulang belakang akibat posisi mengangkat gerobak yang membungkuk dan dilakukan secara berulang sehingga oksigen menuju bagian otot tidak cukup yang menyebabkan penimbunan asam laktat hingga timbul kelelahan otot-otot skeletal yang dirasakan pekerja sebagai bentuk kenyerian otot oleh pekerja (Takala, 2016).

Produktivitas kerja merupakan perbandingan antara jumlah luaran (berat pasir yang diangkut oleh pekerja dengan berat yang tetap, yaitu $70 \mathrm{~kg}$ sekali muatan) dengan masukan (skor keluhan muskuloskeletal) dan waktu (rerata lamanya waktu yang dibutuhkan dalam proses pengangkutan pasir dengan dengan jarak tempuh yang sama). Dalam hal ini produktivitas secara ergonomis dikaji dari aspek manusia yang bekerja sebagai subjek penelitian.

Tabel 7

Analisis Efek Perlakuan terhadap Produktivitas Kerja

\begin{tabular}{cccccc}
\hline \multirow{2}{*}{ Variabel } & \multicolumn{2}{c}{ Periode 1} & \multicolumn{2}{c}{ Periode 2 } & \multirow{2}{*}{ p } \\
\cline { 2 - 5 } & Rerata & SB & Rerata & SB & \\
\hline Produktivitas kerja & 0,067 & 0,001 & 0,071 & 0,002 & 0,001 \\
\hline
\end{tabular}

Tabel 7 menunjukkan bahwa adanya peningkatan produktivitas kerja secara signifikan setelah diberikan perlakuan pada periode 2 sebesar 5,97\%. Nilai produktivitas dipengaruhi oleh perbaikan respons fisiologi berupa keluhan muskuloskeletal yang menurun setelah pekerja melakukan perbaikan sikap kerja yang ergonomis. Peningkatan yang terjadi cukup rendah karena menggunakan variabel keluhan muskuloskeletal yang penurunannya relatif rendah namun tetap signifikan. Walaupun peningkatan produktivitas tergolong rendah namun secara statistik menunjukkan bahwa terjadi peningkatan yang signifikan. Hal tersebut menunjukkan bahwa perbaikan sikap kerja yang ergonomis mampu meningkatkan produktivitas pekerja bangunan di Denpasar Bali. Hal ini sesuai dengan penelitian lain yang menyatakan bahwa perbaikan kondisi kerja melalui pendekatan ergonomi total mampu meningkatkan produktivitas sebesar 61,36\% (Adiatmika, 2007). Perbaikan sikap kerja pada proses pembersihan garam menyebabkan terjadi peningkatan produktivitas kerja (Suarbawa, 2017). Produktivitas dapat meningkat apabila semua sistem dapat dirancang secara ergonomis sehingga mampu dengan waktu yang sama memperoleh hasil kerja lebih besar atau output lebih besar dibandingkan input (Manuaba, 2003).

\section{SIMPULAN}

Disimpulkan bahwa sikap kerja yang lebih ergonomis menurunkan gaya kompresi pada L5/S1 sebesar 73,79\% dan pada L4/L5 sebesar 64,34\%, menurunkan keluhan muskuloskeletal sebesar 4,92\%, dan meningkatkan produktivitas sebesar 5,97\% pada pekerja bangunan di Denpasar Bali.

Berdasarkan simpulan tersebut, hendaknya penggunaan sikap kerja yang ergonomis dilakukan oleh seluruh pekerja bangunan dan dilakukan secara berkelanjutan agar pekerja terhindar dari berbagai penyakit akibat kerja dan mampu meningkatkan produktivitas kerja. 


\section{UCAPAN TERIMA KASIH}

Penulis mengucapkan terima kasih kepada Program Pascasarjana Universitas Udayana, pembimbing dan penguji yang tidak lelah untuk memberi masukan, saran dan koreksi sehingga tuisan ini dapat diselesaikan sebagai bagian dari tesis yang telah diuji oleh Tim Penguji. Terimakasih pula kepada pemilik rumah dan pekerja bangunan serta semua pihak yang telah membantu dan berkontribusi dalam penelitian ini.

\section{DAFTAR PUSTAKA}

Adiatmika, I. P. G. 2007. "Perbaikan Kondisi Kerja dengan Pendekatan Ergonomi Total Menurunkan Keluhan Muskuloskeletal dan Kelelahan serta Menigkatkan Produktivitas dan Penghasilan Pengrajin Logam di Kediri Tabanan" (disertasi). Denpasar: Program Studi Doktor Ilmu Kedokteran, Universitas Udayana.

Andreani, M. U. dan Paskarini, I. 2013. Sikap Kerja yang Berhubungan dengan Keluhan Subjektif pada Penjahit di Jalan Patua Surabaya. Jurnal Promkes, Vol. 1(2): 205-208.

Dinata, I M. K. 2018. "Aplikasi Alat Penuang Berbasis Ergonomi Total Memperbaiki Respons Fisiologis dan Meningkatkan Produktivitas Pekerja Industri Roti Kukus di Denpasar" (disertasi). Denpasar: Program Studi Doktor Ilmu Kedokteran, Universitas Udayana.

Kroemer, K. H. E. dan Grandjean, E. 2000. Fitting the tasks to the human, $5^{\text {th }} \mathrm{ed}$. London: Taylor dan Francis Inc.

Manuaba, A. 2000. Ergonomi, kesehatan dan keselamatan kerja. Proseding Seminar Nasional Ergonomi. Surabaya: Guna Widya.

Manuaba, A. 2003. Penerapan Ergonomi Meningkatkan Produktivitas. Makalah. Denpasar: Bagian Ilmu Faal Fakultas Kedokteran Universitas Udayana.

Muliarta, I M. 2015. Perbaikan Cara Angkat Angkut Material Bangunan Mengurangi Aktivitas Listrik Otot Erector Spinae dan Keluhan Muskuloskeletal Tukang Bangunan. Jurnal Ergonomi Indonesia, Vol. 1(1): 13-14.

Pheasant, S. 1991. Ergonomics Work and Health. London: Macmillan Press Scientific dan Medical.

Rochman, T., Apriyadi, A., dan Astuti, R. D. 2015. Perbaikan Metode Kerja Dengan Pendekatan Metode Rappid Upper Limb Assessment dan Biomekanika Operator Pemindah Peti Buah di Pasar Tradisional. Jurnal Ilmiah Teknik Industri dan Informasi, Vol. 4(1):3-14.

Sitanggang, S. M. 2009. "Usulan Perbaikan Postur dalam Menggunakan Alat Gendong Anak dengan Biomekanika" (skripsi). Solo: Jurusan Teknik Industri Fakultas Teknik Universitas Sebelas Maret

Suarbawa, I K. G. dan Bangse, I K. 2017. Perbaikan Sikap Kerja Pada Proses Pembersihan Garam Amed dapat Menurunkan Beban Kerja, Keluhan Otot dan Kelelahan serta Meningkatkan Produktivitas Kerja. Prosiding Seminar Hasil Penelitian (SNP2M) 2017. Denpasar:

Suputra, I. G.N. B. 2003. "Pemakaian Tempat Duduk Dan Meja Kerja Mengurangi Keluhan Muskuloskeletal dan Meningkatkan Produktivitas Kerja Pemahat Roster Batu Padas Palimanan Di Perusahaan Mahkota Bali” (tesis). Denpasar: Program Pascasarjana Universitas Udayana.

Takala, E. P. 2016. Pathophysiological Mechanism of Musculoskeletal Disorder. Journal of Work, Environment dan Health. Finnish Institute of Occupational Health. 